\title{
How relevant is food craving to obesity and its treatment?
}

\author{
Marc N. Potenza ${ }^{1 *}$ and Carlos M. Grilo² \\ 1 Departments of Psychiatry, Neurobiology and Child Study Center, Yale University School of Medicine, New Haven, CT, USA \\ ${ }^{2}$ Department of Psychiatry and Psychology, Yale University, New Haven, CT, USA \\ *Correspondence: marc.potenza@yale.edu \\ Edited by: \\ Adrian Meule, LWL University Hospital of the Ruhr University Bochum, Germany \\ Reviewed by: \\ Claudio Imperatori, European University of Rome, Italy \\ Martin Grosshans, Central Institute of Mental Health, Germany
}

Keywords: food addiction, food craving, naltrexone, bupropion, obesity, binge-eating disorder

Cravings represent strong motivational states that are characterized by intense desires typically relating to the anticipation of consuming pleasure-producing substances or engaging in hedonic behaviors. In considering food craving and the extent of its applicability to food, a brief review of the history of craving within a culture-sensitive framework appears warranted. Many cultures appear to have considered cravings in different contexts over time, although it has been contended, based on analyses of translations and lexicalization across languages, that craving may fail to translate outside of Europe and North America, although there are similarities in the use of craving and addiction across domains of use (1). The word "crave" is derived from the Old English crafian meaning to beg ${ }^{1}$. Over time, the term craving became linked to excessive patterns of substance use. For example, in the early nineteenth century, in conceptualizing excessive patterns of alcohol consumption, the term dipsomania (translated from the German term Trunksucht, or drinking addiction) was described to define alcoholism as a condition characterized by a craving for continued intoxication (2). In Buddhism, the term taṇhā is commonly translated to mean craving (although its literal translation is "thirst"), with kāmatanhā (sense-craving) describing strong motivations to experience pleasant feelings or sensory pleasures ${ }^{2}$. In Buddhism, tanhā is seen as a type of ignorant desire and a cause of suffering and negative affective states, and some current approaches to understanding treatment mechanisms and promoting treatment development in addictions have involved considering craving within a Buddhist context $(3,4)$. Thus, links between cravings and negative processes including addictions have a longstanding history across multiple cultures.

In current psychiatric conceptualizations of addictions, cravings are considered an important component. Although substance-use disorders have been included in prior editions of the Diagnostic and Statistical Manual, a change from DSM-IV to DSM-5 involved the addition of an inclusionary criterion targeting craving in the diagnosing of substanceuse disorders $(5,6)$. Despite the only recent addition of craving to the formal diagnostic criteria for substance-use disorders, craving has long been considered an important and clinically relevant feature of substance-use disorders. Craving has, for example, been linked in important fashions to treatment outcomes for both pharmacological interventions [e.g., naltrexone in the treatment of alcohol dependence (7)] and behavioral therapies [e.g., cognitivebehavioral therapies (8)] for substance addictions. Findings linking craving and treatment outcomes also appear applicable to non-substance or behavioral addictions; for example, in individuals with pathological gambling receiving opioid-receptor antagonists (naltrexone or nalmefene), individuals with strong gambling urges or cravings at treatment onset were more likely to demonstrate a better treatment outcome (9).

Despite the apparently widely appreciated relevance of craving to substance-use disorders and their treatment, the relevance of addiction features, including craving, to eating behaviors and conditions relating to excessive eating [e.g., obesity or bingeeating disorder (BED)] is more controversial and a topic of considerable debate (1013). Some investigators have posited that energy balance remains central to obesity and that addiction or related aspects may represent a relatively minor component (13). Other investigators have suggested that a rapidly changing food environment may be contributing to the increases in obesity that have been observed over the past $30-40$ years (14). Specifically, given the relative abundance and availability of inexpensive foods, it is possible that motivations to consume highly palatable foods, and perhaps large portions thereof, have taken a larger role in contributing to eating behaviors than in years past when the motivation to eat may have been more closely linked to energy restoration (15). Thus, examining other addiction-related constructs, such as food craving, as they relate to obesity and other food-related conditions seems relevant.

Multiple and diverse studies suggest that food cravings may be clinically relevant to understanding aspects of obesity and associated forms of disordered eating such as BED. Naturalistically and clinically, many individuals with overeating concerns and with BED report seeking

${ }^{1}$ http://www.thefreedictionary.com/crave

${ }^{2}$ http://en.wikipedia.org/wiki/Ta\%E1\%B9\%87h\%C4\%81 
and attending groups such as Overeaters Anonymous and other addiction-based 12-step programs (16). Researchers have developed specific measures to assess food addiction constructs [e.g., the Yale Food Addiction Scale, which has been investigated and validated to varying degrees across different clinical, age, racial, and cultural groups (17-22)] and, more specifically, various models and aspects of "food craving" (23-25) in order to investigate relationship with clinically relevant measures. For example, food craving has been linked to body mass index and consumption of multiple types of foods (sweet, high-fat, carbohydrate/starches, and fastfood) in community-dwelling individuals (26) and to various non-clinical and clinical study groups of individuals following dietary restrictions (27-29). Food cravings may also discriminate between successful and unsuccessful dieters $(30,31)$. Environmental factors like stress may induce food cravings and influence eating behaviors (32), and such effects may be particularly relevant to women $(33,34)$.

Importantly, relationships between food cravings and clinically relevant measures may differ in specific groups (25). For example, studies have reported significant differences in food cravings and associated clinical features between obese persons with and without $\operatorname{BED}(24,25,35,36)$. As expected, individuals who endorse "food addiction" symptoms also report higher food cravings (37). Consistent with some research suggesting similarities in craving across different consummatory behaviors and addictions (38), research has found similarities in food cravings between women with obesity and women who smoke tobacco (39) and higher frequencies of substance-use disorders among obese women with BED who smoke than do not smoke (40).

Relationships between food cravings and various biological variables perhaps differing across specific groups have also been reported. For example, food-craving responses to favorite-food cues were associated with measures of insulin resistance in individuals with obesity but not in those of lean body mass, with thalamic brain activation mediating this relationship in the group with obesity (41). These findings suggest a biological mechanism linking insulin resistance and food cravings in obesity that might involve the thalamus, a region shown to differ in obese and lean humans in norepinephrine transporter availability (42). As such it is tempting to speculate that drugs targeting noradrenergic systems might be helpful in targeting food cravings in obesity, although this remains speculative and warrants further investigation. However, other systems [e.g., involving dopamine release (43)] appear differentially linked to food craving in obesity, suggesting contributions from multiple biological systems to food cravings. Additional, non-mutually exclusive pathways appear differentially linked to food craving and regional brain activations in obese and non-obese individuals. For example, the naturally occurring satiety lipid oleoylethanolamide appears differentially linked to body-mass-index measures in obese and lean individuals and to show different relationships with insular activations in response to food cues (44). Furthermore, molecular entities linked to appetite regulation and body habitus (e.g., leptin, ghrelin) appear differentially associated with regional brain activations to food cues in obese versus non-obese individuals and implicated in substance-use disorders $(45,46)$. These findings raise the possibility that common mechanisms may underlie craving states in obesity and substance-use disorders. Consistent with this possibility, metaanalyses of brain imaging data suggest common contributions of multiple brain regions to drug and food cravings (47). These commonalities have implications for treatment development in that treatments may be applicable to multiple disorders involving craving. Consistent with this idea, data suggest that manipulation of brain function (e.g., through neurostimulation of dorsolateral prefrontal cortex) may decrease food cravings like they do drug cravings (48).

Food cravings may be particularly relevant to individuals with obesity and eating disorders, and some interventions have targeted the management of food cravings. For example, food craving prior to food exposure has been linked to food consumption in obesity and to heightened levels in BED, raising the possibility that it has been targeted in treatment of the disorder (36). Notably, the Food and Drug Administration in the United States has recently approved a new medication combination of naltrexone and bupropion for the treatment of obesity. This follows several large studies reporting that the combination of these two medications, thought each to have some anti-craving effects, were effective in promoting weight loss in obese patients [e.g., Ref. $(49,50)]$. However, to date, various other medications thought to reduce cravings have had limited effects on obese patients with BED (51-53). One study has found cognitive-behavioral therapy to be associated with better treatment outcomes and reduced food cravings in morbidly obese individuals undergoing bariatric surgery (54), and another study found that modifying a dialectical behavioral therapy by including appetite awareness and coping resulted in greater reductions in binge eating in patients with bulimia nervosa (55). Consistent with Buddhist views on craving described above, mindfulness-based approaches have shown promise with respect to reducing food cravings in some studies (56) and weight (57). However, other studies appear less promising (58), raising the possibility that there may exist individual differences with respect to who might respond favorably to these interventions [e.g., perhaps with respect to levels of food suppression thoughts (59) or susceptibility to the presence of food (60), with the possibility of gender-related differences also warranting consideration (61)]. The extent that behavioral techniques that target craving and methods of coping with craving are effective in the treatment of obesity and binge eating in different groups of individuals warrants additional investigation [e.g., (55)]. An alternate intervention, transcranial direct current stimulation of the prefrontal cortex, has been found in several studies to temporarily reduce craving (particularly in less impulsive individuals) and help them possibly resist food consumption $(62,63)$, although larger and more systematic studies are warranted to examine the clinical utility of this approach.

Food-craving states also warrant consideration within a developmental context. For example, upon food cue exposure in a group of children, adolescents and young adults, older age was associated with less craving, less recruitment of the striatum and greater recruitment of prefrontal cortex, and greater frontostriatal coupling 
(64). Adolescents have also shown less cortical activation in response to favorite-food cues as compared with adults $(41,65)$, with certain vulnerable groups of youth (for example, those with prenatal cocaine exposure) showing differences in striatal responses to favorite-food cues (66). The implications of these neurodevelopmental findings that examine responses to favorite-food cues and subjective craving responses on subsequent weight gain and the development (or not) of obesity or eating disorders remains to be more precisely elucidated.

In summary, food craving appears to be an important construct to consider, particularly within the current food environment. Approaches that might effectively target food cravings hold significant implications for advancing public health and clinical concerns relating to overeating.

\section{ACKNOWLEDGMENTS}

National Institute On Drug Abuse (NIDA) grants P50 DA09241, P20 DA027844 and R01 DA035058, a Center of Excellence grant from the National Center for Responsible Gaming, and the National Institute of Diabetes and Digestive and Kidney Diseases (NIDDK) grant K24 DK070052. The contents of the manuscript were generated independently from individuals within the funding agencies and may not represent the views of the funding agencies.

\section{REFERENCES}

1. Hormes JM, Rozin P. Does "craving” carve nature at the joints? Absence of a synonym for craving in many languages. Addict Behav (2010) 35:459-63. doi:10.1016/j.addbeh.2009.12.031

2. Kielhorn F-W. The history of alcoholism: BrühlCramer's concepts and observations. Addiction (1996) 91:121-8. doi:10.1111/j.1360-0443.1996. tb03167.x

3. Brewer JA, Elwafi HM, Davis JH. Craving to quit: psychological models and neurobiological mechanisms of mindfulness training as treatment for addictions. Psychol Addict Behav (2013) 27:366-79. doi:10.1037/a0028490

4. Chen G. The meaning of suffering in drug addiction and recovery from the perspective of existentialism, Buddhism and the 12-step program. J Psychoactive Drugs (2010) 42:363-75. doi:10.1080/ 02791072.2010.10400699

5. American Psychiatric Association. Diagnostic and Statistical Manual of Mental Disorders. Fourth Edition-Test Revision. Washington, DC: American Psychiatric Association (2000).

6. American Psychiatric Association. Diagnostic and Statistical Manual of Mental Disorders. Fifth Edition. Washington, DC: American Psychiatric Association (2013).
7. Monterosso JR, Flannery BA, Pettinati HM, Oslin DW, Rukstalis M, O’Brien CP, et al. Predicting treatment response to naltrexone: the influence of craving and family history. Am J Addict (2001) 10:258-68. doi:10.1080/105504901750532148

8. Carroll K. A Cognitive-Behavioral Approach: Treating Cocaine Addiction. Rockville, MD: NIDA (1998).

9. Grant JE, Kim SW, Hollander E, Potenza MN. Predicting response to opiate antagonists and placebo in the treatment of pathological gambling. Psychopharmacology (Berl) (2008) 200:521-7. doi:10. 1007/s00213-008-1235-3

10. Avena NM, Gearhardt AN, Gold MS, Wang GJ, Potenza MN. Tossing the baby out with the bathwater after a brief rinse? The potential downside of dismissing food addiction based on limited data. Nat Rev Neurosci (2012) 13:514. doi:10.1038/ nrn3212-cl

11. Brownell KD, Gold MS, editors. Food and Addiction: A Comprehensive Handbook. New York, NY: Oxford University Press (2012).

12. Ziauddeen H, Farooqi IS, Fletcher PC. Food addiction: is there a baby in the bathwater? Nat Rev Neurosci (2012) 13:514. doi:10.1038/ nrn3212-c2

13. Ziauddeen H, Farooqi IS, Fletcher PC. Obesity and the brain: how convincing is the addiction model? Nat Rev Neurosci (2012) 13:279-86. doi:10.1038/ nrn3212

14. Gearhardt AN, Grilo CM, DiLeone RJ, Brownell KD, Potenza MN. Can food be addictive? Public health and policy implications. Addiction (2011) 106:1208-12. doi:10.1111/j.13600443.2010.03301.x

15. Potenza MN. Foreward: The Clinical Relevance of Hedonic Eating. In: Avena NM, editor. Hedonic Eating: How the Pleasurable Aspects of Food Can Affect Appetite. New York, NY: Oxford University Press (Forthcoming).

16. Spitzer RL, Devlin M, Walsh BT, Hasin $D$, Wing $R$, Marcus $M$, et al. Binge eating disorder: a multisite field trial of the diagnostic criteria. Int J Eat Disord (1992) 11:191-203. doi:10.1002/1098-108X(199204)11: 3<191::AID-EAT2260110302>3.0.CO;2-S

17. Flint AJ, Gearhardt AN, Corbin WR, Brownell KD, Field AE, Rimm EB. Food-addiction scale measurement in 2 cohorts of middle-aged and older women. Am J Clin Nutr (2014) 99:578-86. doi:10.3945/ajcn.113.068965

18. Gearhardt AN, Corbin WR, Brownell KD. Preliminary validation of the Yale Food Addiction Scale. Appetite (2009) 52:430-6. doi:10.1016/j. appet.2008.12.003

19. Gearhardt AN, Roberto CA, Seamans MJ, Corbin WR, Brownell KD. Preliminary validation of the Yale Food Addiction Scale for children. Eat Behav (2013) 14:508-12. doi:10.1016/j.eatbeh.2013.07. 002

20. Gearhardt AN, White MA, Masheb RM, Grilo CM. An examination of food addiction in a racially diverse sample of obese patients with binge eating disorder in primary care settings. Compr Psychiatry (2013) 54:500-5. doi:10.1016/j.comppsych.2012. 12.009

21. Gearhardt AN, White MA, Masheb RM, Morgan PT, Crosby RD, Grilo CM. An examination of the food addiction construct in obese patients with binge eating disorder. Int J Eat Disord (2012) 45:657-63. doi:10.1002/eat.20957

22. Granero R, Hilker I, Agüera Z, Jiménez-Murcia S, Sauchelli S, Islam MA, et al. Food addiction in a Spanish sample of eating disorders: DSM5 diagnostic subtype differentiation and validation data. Eur Eat Disord Rev (2014) 22(6):389-96. doi:10.1002/erv.2311

23. Cepeda-Benito A, Gleaves DH, Williams TL, Erath SA. The development and validation of the state and trait food-cravings questionnaire. Behav Ther (2000) 31:151-73. doi:10.1016/S00057894(00)80009-X

24. Innamorati $M$, Imperatori $C$, Balsamo $M$, Tamburello S, Belvederi Murri M, Contardi A, et al. Food cravings questionnaire-Trait (FCQ$\mathrm{T}$ ) discriminates between obese and overweight patients with and without binge eating tendencies: the Italian version of the FCQ-T. J Pers Assess (2014) 96:632-9. doi:10.1080/00223891. 2014.909449

25. White MA, Grilo CM. Psychometric properties of the food craving inventory among obese patients with binge eating disorder. Eat Behav (2005) 6:239-45. doi:10.1016/j.eatbeh.2005.01.001

26. Chao A, Grilo CM, White MA, Sinha R. Food cravings, food intake, and weight status in a community-based sample. Eat Behav (2014) 15:478-82. doi:10.1016/j.eatbeh.2014.06.003

27. Gilhooly CH, Das SK, Golden JK, McCrory MA, Dallal GE, Saltzman E, et al. Food cravings and energy regulation: the characteristics of craved foods and their relationship with eating behaviors and weight change during 6 months of dietary energy restriction. Int J Obes (2007) 31:1849-58. doi:10.1038/sj.ijo.0803672

28. Martin CK, O’Neil PM, Pawlow L. Changes in food cravings during low-calorie and very-low-calorie diets. Obesity (2006) 14:115-21. doi:10.1038/oby. 2006.14

29. Massey A, Hill AJ. Dieting and food craving. a descriptive quasi-prospective study. Appetite (2012) 58:781-5. doi:10.1016/j.appet. 2012.01.020

30. Batra P, Das SK, Salinardi T, Robinson L, Saltzman E, Scott T, et al. Relationship of cravings with weight loss and hunger. Results from a 6 month worksite weight loss intervention. Appetite (2013) 69:1-7. doi:10.1016/j.appet.2013.05.002

31. Meule A, Lutz A, Vogele C, Kubler A. Food cravings discriminate differentially between successful and unsuccessful dieters and non-dieters. Validation of the food cravings questionnaires in German. Appetite (2012) 58:88-97. doi:10.1016/j. appet.2011.09.010

32. Yau Y, Potenza MN. Stress and eating behaviors. Minerva Endocrinol (2013) 38:255-67. Available from: http://www.minervamedica.it/en/ journals/minerva-endocrinologica/article.php? cod=R07Y2013N03A0255

33. Hormes JM, Orloff NC, Timko CA. Chocolate craving and disordered eating. Beyond the gender divide? Appetite (2014) 83C:185-93. doi:10.1016/ j.appet.2014.08.018

34. Macedo DM, Diez-Garcia RW. Sweet craving and ghrelin and leptin levels in women during stress. Appetite (2014) 80:264-70. doi:10.1016/j.appet. 2014.05 .031 
35. Greeno CG, Wing RR, Shiffman S. Binge antecedents in obese women with and without binge eating disorder. J Consult Clin Psychol (2000) 68:95-102. doi:10.1037/0022-006X.68.1.95

36. Ng L, Davis C. Cravings and food consumption in binge eating disorder. Eat Behav (2013) 14:472-5. doi:10.1016/j.eatbeh.2013.08.011

37. Meule A, Kubler A. Food cravings in food addiction: the distinct role of positive reinforcement. Eat Behav (2012) 13:252-5. doi:10.1016/j.eatbeh.2012. 02.001

38. May J, Andrade J, Kavanagh DJ, Feeney GF, Gullo MJ, Statham DJ, et al. The craving experience questionnaire: a brief, theory-based measure of consummatory desire and craving. Addiction (2014) 109:728-35. doi:10.1111/add.12472

39. Pepino MY, Finkbeiner S, Mennella JA. Similarities in food cravings and mood states between obese women and women who smoke tobacco. Obesity (2009) 17:1158-63. doi:10.1038/oby.2009.46

40. White MA, Grilo CM. Psychiatric comorbidity in binge eating disorder as a function of smoking history. J Clin Psychiatry (2006) 67:594-9. doi:10.4088/JCP.v67n0410

41. Jastreboff AM, Sinha R, Lacadie C, Small DM, Sherwin RS, Potenza MN. Neural correlates of stress- and food-cue-induced food craving in obesity: association with insulin levels. Diabetes Care (2013) 36:394-402. doi:10.2337/dc12-1112

42. Li CS, Potenza MN, Lee DE, Planeta B, Gallezot JD, Labaree D, et al. Decreased norepinephrine transporter availability in obesity: positron emission tomography imaging with (S,S)-[11C]Omethylreboxetine. Neuroimage (2014) 86:306-10. doi:10.1016/j.neuroimage.2013.10.004

43. van de Giessen E, Celik F, Schweitzer DH, van den Brink W, Booij J. Dopamine D2/3 receptor availability and amphetamine-induced dopamine release in obesity. J Psychopharmacol (2014) 28:866-73. doi:10.1177/0269881114531664

44. Grosshans M, Schwarz E, Bumb JM, Schaefer C, Rohleder C, Vollmert C, et al. Oleoylethanolamide and human neural responses to food stimuli in obesity. JAMA Psychiatry (2014) 71(11):1254-61. doi:10.1001/jamapsychiatry.2014.1215

45. Jastreboff AM, Lacadie C, Seo D, Kubat J, Van Name MA, Giannini C, et al. Leptin is associated with exaggerated brain reward and emotion responses to food images in adolescent obesity. Diabetes Care (2014) 37(11):3061-8. doi:10.2337/dc14-0525

46. Kroemer NB, Krebs L, Kobiella A, Grimm O, Pilhatsch M, Bidlingmaier M, et al. Fasting levels of ghrelin covary with the brain response to food pictures. Addict Biol (2013) 18:855-62. doi:10.1111/j. 1369-1600.2012.00489.x

47. Tang DW, Fellows LK, Small DM, Dagher A. Food and drug cues activate similar brain regions: a meta-analysis of functional MRI studies. Physiol Behav (2012) 106:317-24. doi:10.1016/j.physbeh. 2012.03.009

48. Jansen JM, Daams JG, Koeter MW, Veltman DJ, van den Brink W, Goudriaan AE. Effects of non-invasive neurostimulation on craving: a meta-analysis. Neurosci Biobehav Rev (2013) 37:2472-80. doi:10.1016/j.neubiorev.2013.07.009

49. Greenway FL, Fujioka K, Plodkowski RA, Mudaliar S, Guttadauria M, Erickson J, et al. Effect of naltrexone plus bupropion on weight loss in overweight and obese adults (COR-I): a multicentre randomized doubleblind placebo-controlled phase 3 trial. Lancet (2010) 376:595-605. doi:10.1016/S0140-6736(10) 60888-4

50. Greenway FL, Whitehouse MJ, Guttadauria M, Anderson JW, Atkinson RL, Fujioka K, et al. Rational design of a combination medication for the treatment of obesity. Obesity (2009) 17:30-9. doi: 10.1038/oby.2008.461

51. McElroy SL, Guerdjikova AI, Blom TJ, Crow SJ, Memisoglu A, Silverman BL, et al. A placebocontrolled pilot study of the novel opioid receptor antagonist ALKS-33 in binge eating disorder. Int J Eat Disord (2013) 46:239-45. doi:10.1002/eat. 22114

52. McElroy SL, Guerdjikova AI, Winstanley EL, O’Melia AM, Mori N, McCoy J, et al. Acamprosate in the treatment of binge eating disorder: a placebo-controlled trial. Int J Eat Disord (2011) 44:81-90. doi:10.1002/eat.20876

53. White MA, Grilo CM. Bupropion for overweight women with binge-eating disorder: a randomized, double-blind, placebo-controlled trial. Clin Psychiatry (2013) 74:400-6. doi:10.4088/JCP. $12 \mathrm{~m} 08071$

54. Abilés V, Abilés J, Rodríguez-Ruiz S, Luna V, Martín F, Gándara N, et al. Effectiveness of cognitive behavioral therapy on weight loss after two years of bariatric surgery in morbidly obese patients. Nutr Hosp (2013) 28:1109-14. doi:10.3305/nh.2013.28. 4.6536

55. Hill DM, Craighead LW, Safer DL. Appetitefocused dialectical behavior therapy for the treatment of binge eating with purging: a preliminary trial. Int J Eat Disord (2011) 44:249-61. doi:10.1002/eat.20812

56. Alberts HJ, Mulkens S, Smeets M, Thewissen R. Coping with food cravings. Investigating the potential of a mindfulness-based intervention. Appetite (2010) 55:160-3. doi:10.1016/j.appet. 2010.05.044

57. Dalena J, Smith BW, Shelley BM, Sloan AL, Leahigh L, Begay D. Pilot study: mindful eating and living (MEAL): weight, eating behavior, and psychological outcomes associated with a mindfulnessbased intervention for people with obesity. Complement Ther Med (2010) 18:260-4. doi:10.1016/j. ctim.2010.09.008

58. May J, Andrade J, Batey H, Berry LM, Kavanagh DJ. Less food for thought. Impact of attentional instructions on intrusive thoughts about snack foods. Appetite (2010) 55:279-87. doi:10.1016/j. appet.2010.06.014

59. Barnes RD, Tantleff-Dunn S. Food for thought: examining the relationship between food thought suppression and weight-related outcomes. Eat Behav (2010) 11:175-9. doi:10.1016/j.eatbeh.2010. 03.001

60. Forman EM, Hoffman KL, McGrath KB, Herbert JD, Brandsma LL, Lowe MR. A comparison of acceptance- and control-based strategies for coping with food cravings: an analog study. Behav Res Ther (2007) 45:2372-86. doi:10.1016/j.brat 2007.04.004

61. Barnes RD, Masheb RM, Grilo CM. Food thought suppression: a matched comparison of obese individuals with and without binge eating disorder. Eat
Behav (2011) 12:272-6. doi:10.1016/j.eatbeh.2011. 07.011

62. Goldman RL, Borckardt JJ, Frohman HA, O’Neil PM, Madan A, Campbell LK, et al. Prefrontal cortex transcranial direct current stimulation (tDCS) temporarily reduces food cravings and increases the self-reported ability to resist food in adults with frequent food craving. Appetite (2011) 56:741-6. doi:10.1016/j.appet.2011.02.013

63. Kekic M, McClelland J, Campbell I, Nestler S, Rubia $\mathrm{K}$, David AS, et al. The effects of prefrontal cortex transcranial direct current stimulation (tDCS) on food craving and temporal discounting in women with frequent food cravings. Appetite (2014) 78:55-62. doi:10.1016/j.appet.2014.03.010 64. Silvers JA, Insel C, Powers A, Franz P, Weber J, Mischel W, et al. Curbing craving: behavioral and brain evidence that children regulate craving when instructed to do so but have higher baseline craving than adults. Psychol Sci (2014) 25(10):1932-42. doi:10.1177/0956797614546001

65. Hommer RE, Seo D, Lacadie CM, Chaplin TM, Mayes LC, Sinha R, et al. Neural correlates of stress and favorite-food cue exposure in adolescents: a functional magnetic resonance imaging study. Hum Brain Mapp (2013) 34:2561-73. doi:10.1002/hbm.22089

66. Yip SW, Potenza EB, Balodis IM, Lacadie CM, Sinha R, Mayes LC, et al. Prenatal cocaine exposure and adolescent responses to appetitive and stressful stimuli. Neuropsychopharmacology (2014) 39:2824-34. doi:10.1038/npp.2014.133

Conflict of Interest Statement: Dr. Potenza reports no conflicts of interest with respect to the content of this manuscript. He has received financial support or compensation for the following: Dr. Potenza has consulted for and advised Somaxon, Boehringer Ingelheim, Lundbeck, Ironwood, Shire, and INSYS; has received research support from the National Institutes of Health, Veteran's Administration, Mohegan Sun Casino, the National Center for Responsible Gaming, and Forest Laboratories, Ortho-McNeil, Oy-Control/Biotie, Glaxo-SmithKline, and Psyadon pharmaceuticals; has participated in surveys, mailings, or telephone consultations related to drug addiction, impulse control disorders or other health topics; has consulted for law offices and the federal public defender's office in issues related to impulse control disorders; provides clinical care in the Connecticut Department of Mental Health and Addiction Services Problem Gambling Services Program; has performed grant reviews for the National Institutes of Health and other agencies; has guest-edited journal sections and journals; has given academic lectures in grand rounds, CME events, and other clinical or scientific venues; and has generated books or book chapters for publishers of mental health texts. Dr. Grilo reports no conflicts of interest with respect to this manuscript. Dr. Grilo reports that he has received research support from the National Institutes of Health and Medical Research Foundations, has received honoraria for academic grand rounds and lectures at universities and professional conferences, has received honoraria for CME events and lectures, has received honoraria for academic journal editorial roles, has received consultant and advisory fees from Shire, and has received book royalties for academic books. 
Received: 14 October 2014; accepted: 06 November 2014; published online: 19 November 2014.

Citation: Potenza MN and Grilo CM (2014)

How relevant is food craving to obesity and its treatment? Front. Psychiatry 5:164. doi:10.3389/fpsyt. 2014.00164
This article was submitted to Eating Behavior, a section of the journal Frontiers in Psychiatry.

Copyright () 2014 Potenza and Grilo. This is an open-access article distributed under the terms of the Creative Commons Attribution License (CC BY). The use, distribution or reproduction in other forums is permitted, provided the original author(s) or licensor are credited and that the original publication in this journal is cited, in accordance with accepted academic practice. No use, distribution or reproduction is permitted which does not comply with these terms. 